\title{
WORK RELATED MUSCULOSKELETAL DISORDERS AMONG PREPARATORY SCHOOL TEACHERS IN EGYPT
}

\author{
By \\ ${ }^{1}$ El Gendy $\mathrm{M}$ and ${ }^{2}$ Korish MM \\ ${ }^{I}$ Department of Basic Science for Physical Therapy, Faculty of Physical Therapy, Cairo University, \\ ${ }^{2}$ Sixth District Medical Center, Nasr City, Cairo, Egypt.
}

\begin{abstract}
Introduction: Preparatory school teachers represent an occupational group who are prone to work related musculoskeletal disorder but its prevalence among teachers in Egypt has not been reported. Aim of work: To determine the prevalence of upper limb, lower limb, neck and back musculoskeletal disorders, to determine the relationship between teachers characteristics and musculoskeletal disorders and to investigate the relationship between physical risk factors and musculoskeletal disorders among preparatory governmental school teachers in Cairo, Egypt in the previous12 months. Materials and methods: Convenience sample of 200 preparatory school teachers were selected from governmental schools in Cairo, Egypt, their mean age value was (35.9 \pm 3.34 ) years, they were asked to answer a modified Nordic questionnaire which assisted musculoskeletal disorder due to their work in last 12 months. Results: The prevalence of work related musculoskeletal disorders among Egyptian preparatory school teachers were $96 \%$ in the previous 12 months. The prevalence was significantly higher among females compared to males. The neck and back $(83.5 \%)$ were the most commonly affected parts followed by upper limb. Standing for long periods of time and high workload were significantly related to upper limb, lower limb, neck and back injuries. About $18.9 \%$ of teachers took sick leave (from 1to 7 days) due to their injuries. Conclusion: the prevalence of work related musculoskeletal disorders among preparatory school teachers in Cairo, Egypt is high as in comparison to their counterparts around the world.
\end{abstract}

Key words: Work related musculoskeletal disorder, Modified Nordic questionnaire, Upper limb, Lower limb, Neck and back injuries. 


\section{Introduction}

Work Related Musculoskeletal Disorders (WRMSDs) represent one of the most common occupational health problems in both developed and developing countries. Musculoskeletal disorders (MSD) an umbrella term for which repetitive strain injury, repetitive trauma disorder and cumulative trauma disorder are all used interchangeably. Work related musculoskeletal disorders may progress in stages from mild to severe. The earlier people notice symptoms, the quicker they should respond to them (Szabo \& King, 2000).

(MSD) represents one of the most common and important occupational health problems in the teaching profession, which although long neglected, has attracted increasing concern in recent years. By definition, MSD include a wide range of inflammatory and degenerative conditions affecting the muscles, joints, tendons, ligaments, nerves, bones and the localized blood circulation system, that may be caused by or aggravated by work tasks and by the effects of the immediate environment in which work is carried out. School teachers in general, have been demonstrated relative to other occupational groups, to report high rates of MSD of between $40 \%$ and $95 \%$. The work of a teacher involves not only teaching students, but also preparing lessons, assessing students' work. These activities may cause teachers to suffer adverse mental and physical health issues due to their unique and wide variety of job functions(Erick \& Smith, 2015).

If there is no enough time for recovery, pain symptoms that account for the high levels of absenteeism due to health conditions in this group of workers are triggered or prompted. Thus, teaching leads to stress, with consequences to physical and mental health and with an impact on professional performance (Jefferson et al., 2009).

The work tasks of school teachers often involves significant use of a 'head down' posture, such as frequent reading, marking of assignments, and writing on a blackboard(Erick \& Smith, 2011)

Musculoskeletal complaints, especially of the lower back, neck and shoulders, are also common among teachers due to prolonged desk work, prolonged standing in class and repetitive overhead writing on the board, prolonged sitting resulting from frequent reading, 
preparation of lessons and marking of assignments, and working on a computer (Shuai et al. , 2014).

MSD decrease productivity at work due to sick leave, absenteeism and early retirement, and are also costly in terms of treatment and individual suffering(Erick \& Smith, 2011).

A study in Ireland showed that one of the leading causes for ill health retirement among school teachers was musculoskeletal problems, which contributed to $10 \%$ of the ill health retirement in the population (Mengestu, 2013).

Most of literature used the survey method to ascertain the occupational health problems and risk factors within a population.

\section{Aim of work}

To determine the prevalence of upper limb, lower limb, neck and back musculoskeletal disorders, to determine the relationship between teachers characteristics and musculoskeletal disorders and to investigate the relationship between physical risk factors and musculoskeletal disorders among preparatory governmental school teachers in Cairo, Egypt in the previous12 months.

\section{Materials and methods}

- Study design: it is cross sectional study

- Place and duration of the study: the study was carried out in governmental preparatory schools in Cairo, Egypt during the period from October 2015 till May 2016.

- Study sample: Two hundred (males and females) teachers participated in the study. They were selected by using convenience sampling technique from preparatory governmental schools who work for full time in Cairo, Egypt.

Inclusion criteria for the study group:

1. Age ranged between 30 and 40 .

2. Both males and females.

3. Teachers who work in preparatory governmental schools for full time ( 7 hours per day almost) in Cairo, Egypt.

4. Teachers experience from 5to 10 years. 
Exclusion criteria for both groups:

1. Teachers who had musculoskeletal abnormalities due to other causes not work related (i.e. congenital, traumatic).

2. Teachers with previous operation involving locomotors system.

\section{- Study methods:}

A self-administered questionnaire is a valid and relatively inexpensive way to establish baseline risk identification information for an occupational group (Adegoke et al.,2008, Alrowayeh et al., 2010). Standardized Nordic Musculoskeletal Questionnaire is a valid and reliable questionnaire (Kuorinka et al., 1987 , Crawford, 2007) was developed from a project funded by the Nordic Council of Ministers, because they need standardized questionnaire methodology allowing comparison of low back, neck, shoulder and general complaints for use in epidemiological studies (Palmer et al, 1999)

\section{- Procedure of the Study:}

Two hundred copies of the questionnaire were given to selected teachers who work for full time in preparatory governmental schools in Cairo, Egypt for self-administration.

\section{Consent}

Authors declare that verbal consent was taken from the studied group before making the study.

\section{Ethical approval}

The ethical committee of Faculty of Physical Therapy approved the study protocol.

\section{Data management}

- Descriptive statistics was used to estimate the prevalence of work related musculoskeletal disorders , demographic characteristics and physical risk factors.

- Chi- square tests also were used to assist relationship between work related musculoskeletal disorders and teachers' characteristics and between musculoskeletal disorders and physical risk factors of work.

- Frequencies and crosstabulations were used to compare musculoskeletal disorders prevalence and demographics, work history and physical risk factors. Frequency and percentages of responses to the Nordic Questionnaire also were calculated. 
- Arithmetic averages: It was calculated the 4 points Liker scale through:

- The arithmetic average (weighted mean $)=\mathrm{K}$ (Always) $\mathrm{x} 4+\mathrm{K}$ (Often) x $3+\mathrm{K}$ (Sometimes) x $2+$ (Never) $\mathrm{x} 1 / \mathrm{n}$

- After calculating the weighted mean, the attitude was measured according to 4 points like scale measure as following:

\begin{tabular}{|l|l|}
\hline Weighted mean & Level \\
\hline from 1.00 to 1.74 & Never (1) \\
\hline from 1.75 to 2.49 & Sometimes (2) \\
\hline from 2.50 to 3.24 & Often (3) \\
\hline from 3.25 to 4.00 & Always (4) \\
\hline
\end{tabular}

- Correlation between the ranked data variables was calculated by Spearman>s.

- Level of significance will be set at $\leq$ 0.05 . 


\section{Results}

The study was performed on a convenience sample of 200 subjects $83(41.5 \%)$ males and 117 (58.5\%) females.

Table (1): Demographic characteristics of the preparatory governmental school teachers:

\begin{tabular}{|l|c|c|c|c|c|c|c|c|}
\hline Number & Age & Height & Weight & BMI & $\begin{array}{c}\text { Years of } \\
\text { experience }\end{array}$ & $\begin{array}{c}\text { Classes } \\
\text { per day }\end{array}$ & $\begin{array}{c}\text { Classes } \\
\text { per } \\
\text { week }\end{array}$ & $\begin{array}{c}\text { No. of } \\
\text { students in } \\
\text { the class }\end{array}$ \\
\hline Mean & 35.93 & 167.54 & 76.82 & 27.20 & 7.19 & 5.20 & 25.99 & 40.61 \\
\hline S.D. \pm & 3.34 & 7.94 & 12.55 & 3.39 & 2.65 & 0.70 & 3.60 & 4.71 \\
\hline Max. & 40 & 185 & 110 & 38 & 10 & 6 & 36 & 50 \\
\hline Min. & 30 & 152 & 47 & 18 & 2 & 3 & 15 & 30 \\
\hline
\end{tabular}

Table (1) : showed that the mean ages of the studied group was $(35.9 \pm 3.34)$ years, Height was (167.54 \pm 7.94), Weight was (76.82 \pm 12.55$)$, BMI was (27.2 \pm 3.39$)$, Classes per day was (5.20 \pm 0.70$)$, and Classes per week was $(25.99 \pm 3.60)$ and No. of students in the class was $(40.61 \pm 4.71)$. 
Table (2): Frequency distribution and mean value of total response to musculoskeletal risk factors (MSRF) questionnaire among teachers in Egypt:

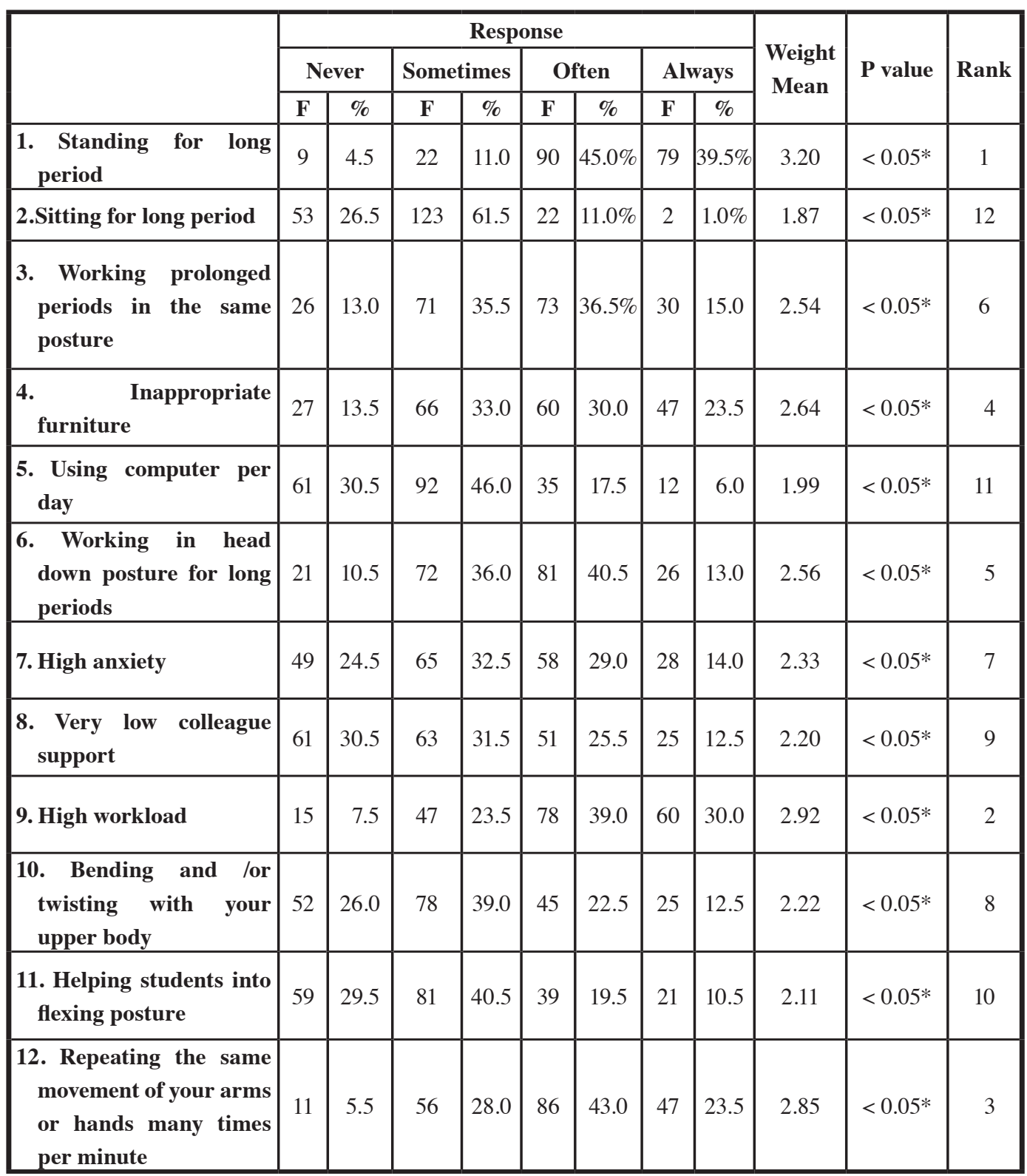

*:Statistically significant. 
Table (3): Correlation between works related musculoskeletal disorders and teacher's general characteristic in Egypt:

\begin{tabular}{|l|c|c|c|}
\hline & Pain in upper limb & Pain in lower limb & Pain in back \\
\hline Coefficient & 0.144 & $\begin{array}{c}\text { Correlation } \\
\text { Coefficient }\end{array}$ & $\begin{array}{c}\text { Correlation } \\
\text { Coefficient }\end{array}$ \\
\hline Age & $-0.333^{* *}$ & $0.229^{*}$ & 0.185 \\
\hline Height & $-0.332^{* *}$ & 0.084 & -0.085 \\
\hline Weight & -0.172 & $0.249^{* *}$ & -0.105 \\
\hline BMI & 0.140 & $0.247^{*}$ & -0.014 \\
\hline Years of experience & 0.056 & $0.224^{*}$ & 0.147 \\
\hline Classes per day & 0.046 & $-0.192^{*}$ & -0.102 \\
\hline Classes per week & 0.039 & $-0.229^{*}$ & -0.130 \\
\hline $\begin{array}{l}\text { No. of students in the } \\
\text { class }\end{array}$ & & -0.088 & -0.111 \\
\hline
\end{tabular}

(*) P-value $<0.05$

(**) $\mathrm{P}$-value $<0.01$

Table (4): Prevalence of work related musculoskeletal disorder in one two or three body parts among teachers in Egypt.

\begin{tabular}{|l|r|r|r|r|r|r|r|r|}
\hline \multirow{2}{*}{$\begin{array}{c}\text { From total number of } \\
\mathbf{2 0 0} \text { teachers }\end{array}$} & \multicolumn{7}{|c|}{$\begin{array}{c}\text { Hesponse no } \\
\text { problem }\end{array}$} & \multicolumn{2}{|c|}{$\begin{array}{c}\text { Have problem } \\
\text { in one body } \\
\text { part }\end{array}$} & $\begin{array}{c}\text { Have } \\
\text { problem in } \\
\text { two body } \\
\text { parts }\end{array}$ & $\begin{array}{c}\text { Have } \\
\text { problem in } \\
\text { three body } \\
\text { parts }\end{array}$ \\
\cline { 2 - 9 } & $\mathbf{F}$ & $\mathbf{\%}$ & $\mathbf{F}$ & $\mathbf{\%}$ & $\mathbf{F}$ & $\mathbf{F}$ & $\mathbf{\%}$ \\
\hline $\begin{array}{l}\text { Have you ever } \\
\text { complaint due to work } \\
\text { in one two or three } \\
\text { body parts? }\end{array}$ & 8 & $4.0 \%$ & 47 & $23.5 \%$ & 102 & $51.0 \%$ & 43 & $21.5 \%$ \\
\hline
\end{tabular}

Table (4) showed that $102(51 \%)$ of teachers had complaints in two body parts. 


\section{Discussion}

School teachers represent an occupational group, in which the prevalence of musculoskeletal disorders, in different body sites, appears to be high.

The findings from the current study are alarming as it is much higher than results of previous studies. About $96 \%$ of the participating teachers complained of WRMSDs which is higher in comparison with the reported prevalence of WRMSDs among teachers in china $85 \%$ (Yue, Liu, \& Li, 2012), in Botswana83.3\% (Erick \& Smith, 2014) in Recife the capital of Pernambuco State in Brazil $73.5 \%$ (de Ceballos \& Santos, 2015) ,Turkey 51.4\%(Korkmaz, Cavlak, \& Telci, 2011).The school teachers of Turkey, China, Australia, Brazil, Sweden, USA, Germany, Estonia, Japan, Malaysia, Philippines, France and Greece have proven that related to other working groups, a great occurrence of MSD was noted between $40 \%$ and $95 \%$ among them (Mesaria \& Jaiswal, 2015). In Hong Kong (Ey \& Ah, 2010) detected that $99.5 \%$ of respondents suffered at least one type of complaint .

From the result of this survey, it could be noticed higher prevalence neck and back, upper and lower limbs complaint among females than males. These findings were consistent with the study done by (Erick \& Smith, 2011) who detected that the prevalence of MSD is positively associated with female gender as they found a significant higher prevalence of WRMSDs among females compared to males between school teachers in Botswana (Erick \& Smith, 2014). Also in a study done by Jefferson et al, 2009, they found that the prevalence of MSDSs in Poland was higher among females then males.

The result of our study reported that the work related musculoskeletal disorders had no relationship with age. The fact is concerning, because younger teachers seem to be having pain early. A study done by (Jefferson et al., 2009) showed that younger workers face greater work demands, being exposed to risk factors, as they take over more activities and tasks in the beginning of the career.

The result of our study indicate high prevalence of work related musculoskeletal disorders due to the daily work being performed by the teachers which may contribute to stress in these anatomical areas, such as prolonged 
standing, high work load, working in the same position for long periods, working in head down posture for long periods, repeating the same movement in hand many times per minute (Table 2).

The prevalence of MSDs is related to variables of teaching activities, including working time, number of students per class, weekly schedule, physical exertion, heat, furniture, and high demand(de Ceballos \& Santos, 2015).

There is no statistically significant relationship between body mass index( BMI) and upper limb, neck or back pain. There was statistically significant relationship between pain in lower limb and BMI (Table 3) .Our results were similar with the study done by (Rottermund et al., 2015); who found that there is no association between the BMI and disability of the spine back and neck.

There was statistically significant relationship between pain in lower limb and classes per day and classes per week with P-value <0.05 (Table 3). There was no statistically significant relationship between pain in neck, back, upper limb and classes per day, classes per week (Table 3) These results were similar to a study done in China about the relation between hours of work per week and MSDs , they detected that there were no association with both neck, shoulder ,low back pain and hours of work (Yue et al., 2012). These results contradicted with previous studies that found long weekly working hours expose teachers to factors such as prolonged standing, prolonged sitting or awkward posture all of which have been associated with back pain (Murthy \& Mitra, 2015)

There was no statistically significant relationship between pain in neck and or back, upper limb and lower limb with number of students in the class (Table $3)$. These results are contradicted with a previous studies which found that there is a significant relationship between pain in neck and or back, upper limb and lower limb and more than 30 students per class(Jefferson et al., 2009).

About $96 \%$ of the studied group was complaining of MSD. Out of these, $47(23.5 \%)$ had only one complaint, 102(51\%) had two complaints, $43(21.5 \%)$ had three complaints (Table4).

This was concomitant with the study done by (de Ceballos \& Santos, 2015) on 386 teachers . Out of these, 152 (29.0\%) 
had only one complaint, $151(28.8 \%)$ had two or three complaints, and 83(15.9\%) had more than three complaints.

These results were consistent with previous results in other countries: a Chinese study was done on school teachers which reported a high prevalence of neck pain $(68.9 \%)$ and shoulder pain $(73.4 \%)$ in the previous month. Another study declared that $42.5 \%$ of Turkish school teachers experienced neck pain and $28.7 \%$ experienced shoulder pain in the previous month. (Erick \& Smith, 2011)

\section{Conclusion}

There were key findings in this study:

1. WRMSDs among teachers in Egypt were common, the back followed by lower limb followed by upper limb disorders.

2. Upper limb disorders were related to, age and BMI but lower limb disorders was not. Professional experience and number of class per day were not related to back, upper limb disorders but were not related to lower limb disorders. Back, upper limb and lower limb were relating to number of students in the classes.
3. Work related musculoskeletal disorders were related some physical risk factors. Back, upper limb and lower limb disorders were affected by standing long periods, high workload and repeating the same movement of the arms or hands many times per minute and inappropriate furniture.

4. These findings underline the importance of having WRMSDs education and prevention programs in Egypt. Early access of treatment and prevention programs may prove effective in reducing these disorders.

\section{Acknowledgements}

The author would like to acknowledge the contribution of all teachers who participated in this study

\section{Conflict of interest}

Authors have declared that no conflict of interest exists.

\section{Reference}

1. Adegoke BO, Akodu AK and Oyeyemi AL (2008): Work-related musculoskeletal disorders among Nigerian physiotherapists. BMC Musculosk Dis; 9:112.

2. Alrowayeh HN, Alshatti,TA ,Aljadi SH, Fares M, Alshamire MM and Alwazan SS (2010): Prevalence, characteristics, and impacts of work-related musculoskeletal disorders: a survey among physical therapists in the State of Kuwait. BMC Musculosk Dis; 11: 116. 
3. Crawford JO (2007): The Nordic Musculoskeletal Questionnaire. Occup Med; 57(4), 300:301.

4. De Ceballos AG, Da C and Santos GB (2015): Factors associated with musculoskeletal pain among teachers: sociodemographics aspects, general health and well-being at work. Braz J Epid; 18(3):702-715.

5. Erick PN and Smith DR (2011): A systematic review of musculoskeletal disorders among school teachers. BMC Musc Dis; 12(1):260.

6. Erick PN, Smith DR (2014): The Prevalence and Risk Factors for Musculoskeletal Disorders among School Teachers in Botswana. Occup Med Health Aff; 2:178. doi:10.4172/23296879.1000178.

7. Erick PN and Smith DR (2015): Musculoskeletal disorders in the teaching profession: an emerging workplace hazard with significant repercussions for developing countries. Ind Health; 53(4):385-386.

8. Ey C and Ah C (2010): Subjective health complaints of teachers from primary and secondary schools in Hong Kong. Int J Occup Saf Ergon; 16 (1):23-39.

9. Jefferson PI, Ribeiro ID, Araújo TM, Carvalho FM and Reis IV (2009): Prevalence of musculoskeletal pain among teachers. Rev Bras Epidemiol; 12(4):1-10.

10. Korkmaz NC, Cavlak U and Telci EA (2011): Musculoskeletal pain, associated risk factors and coping strategies in school teachers; Scientific Research and Essays 6(3) :649-657. ISSN 1992-2248 (C) 2011 Academic Journals .

11. Kuorinka I, Jonsson B, Kilbom A, Vinterberg H, Biering Sørensen F, Andersson G and Jørgensen K (1987): Standardised Nordic questionnaires for the analysis of musculoskeletal symptoms. Ap Erg; 18(3): 233-237.

12. Mengestu MY (2013): Low Back Pain and Associated Factors among Teachers in Gondar
Town, North Gondar, and Amhara Region, Ethiopia. Occup Med Health Aff; 01(05):1-8.

13. Mesaria S and Jaiswal N (2015): Musculoskeletal Disorders among Teachers Residing in Various Nations. A Review. Research Journal of Recent Science; 4: 23-27, ISSN2277-2502 Available at: www.isca.me.

14. Murthy KH and Mitra SK (2015): Evaluation of Safety and Efficacy of Rumaflam Tablets \& Rumaflam Cream in the Treatment of Musculoskeletal Disorders; World Journal of Pharmacy and Pharmaceutical Sciences; 4(10):1309-1317 ;ISSN 2278 - 435.

15. Palmer K, Smith G, Kellingray S and Cooper C (1999): Repeatability and validity of an upper limb and neck discomfort questionnaire: The utility of the standardized Nordic questionnaire. Occup Med; 49(3):171-175.

16. Rottermund J, Knapik A, Saulicz E, Myśliwiec A, Saulicz M, Rygiel K and Linek P (2015): Back and neck pain among school teachers in Poland and its correlations with physical activity. Medycyna Pracy; 66(4), 771:778.

17. Samad (2010): Prevalence of Low Back Pain and its Risk Factors among School Teachers. Am J Ap Sc;7(5), 634:639.

18. Shuai J, Yue P, Li L, Liu F and Wang S (2014): Assessing the effects of an educational program for the prevention of work-related musculoskeletal disorders among school teachers. BMC Public Health;1:9.

19. Szabo RM and King KJ (2000): Repetitive stress injury: diagnosis or self-fulfilling prophecy? J Bone and Joint Surg; 82(9): 1314-22.

20. Woolf AD and Pfleger B (2003): Burden of major musculoskeletal conditions. Bulletin of the World Health Organization; 81(9): 646-656.

21. Yue P, Liu F and Li L (2012): Neck, shoulder pain and low back pain among school teachers in China, prevalence and risk factors. BMC Public Health; 12:789. 